\title{
KAJIAN PERILAKU AGONISTIK INTRAPESIFIK KOLONI Nasutitermes matangesis (ISOPTERA : TERMITIDAE) DI PULAU SEBESI LAMPUNG
}

\author{
Eko Kuswanto, Fatimatuzzahra, dan Darwisah
}

Pendidikan Biologi, Fakultas Tarbiyah dan Keguruan UIN Raden Intan Lampung

Emile : ekokuswantolpg@yahoo.co.id

Diterima : 01 Agustus 2017. Disetujui: 01 Desember 2017. Dipublikasikan: 29 Desember 2017

Abstrak : Penelitian ini bertujuan untuk mengetahui perilaku agonistik intraspesifik koloni Nasutitermes matangensis (Isoptera : Termitidae). Kajian perilaku agonistik intraspesifik koloni Nasutitermes matangensis di Pulau Sebesi Lampung telah dilakukan pada bulan November - Desember 2016. Nasutitermes matangensis merupakan salah satu jenis rayap dari famili termitidae. Penelitian ini tergolong dalam penelitian deskriptif, teknik yang digunakan untuk pengambilan sampel pada penelitian ini adalah Direct sampling yaitu dengan cara pengambilan sampel secara langsung yang dilakukan di Pulau Sebesi Lampung kemudian dilanjutkan dengan Purposive sampling. Berdasarkan hasil penelitian, perilaku agonistik yang terjadi pada individu rayap kombinasi prajurit versus prajurit pada level antenasi dan menghindar, sedangkan perilaku agonistik individu rayap kombinasi pekerja versus pekerja menunjukkan level antenasi, menghindar, dan menyerang, sementara perilaku agonistik individu rayap kombinasi prajurit versus pekerja menunjukkan level antenasi, menghindar, dan menyerang. Semua kombinasi baik prajurit versus prajurit, pekerja versus pekerja, dan prajurit versus pekerja dapat disimpilkan bahwa status agonistik persentase negatif. Perilaku agonistik dinyatakan positif $(+)$ jika persentase perilaku menyerang $\geq 80 \%$ sedangkan jika menyerang $\leq 20 \%$ dinyatakan status agonistik negatif (-).

Kata Kunci : Nasutitermes matangensis, Perilaku Agonistik Intraspesifik, Termitidae.

\section{PENDAHULUAN}

Penelitian ini bertujuan untuk mengetahui perilaku agonistik yang sering terjadi antara organisme satu dengan organisme lain hal ini bertujuan untuk kelangsungan hidup organisme tersebut. Terdapat intraksi dalam ekosistem antara organisme Nasutitermes matangensis intraksi tersebut dapat berupa intraksi positif yang menguntungkan dan dapat berupa intraksi negatif seperti kompetisi. Dalam ekosistem terjadi kompetisi/persaingan antar organisme untuk kelangsungan hidupnya, kompetisi dibagi menjadi dua yaitu kompetisi intraspesifik dan interspesifik. Kompetisi 
intraspesifik, yaitu kompetisi diantara anggota spesies yang sama dan kompetisi interspesifik, yaitu kompetisi diantara anggota yang berbeda spesies.

Perilaku merupakan respons terhadap kondisi internal dan eksternalnya, begitu pula dengan rayap ketika rayap berintraksi dengan rayap dari koloni yang berbeda spesies yang berbeda akan terjadi perilaku agonistik. Perilaku Agonistik merupakan perilaku yang berhubungan dengan mempertahankan diri untuk bertahan hidup, perilaku agonistik dapat juga berupa tingkah laku dalam menarik lawan jenis, fungsi umum dari perilaku agonistik adalah penyesuaian diri dan respon untuk kondisi konflik yang terjadi dalam suatu spesies.

Klasifikasi ilmiah spesies rayap Nasutitermes matangensis adalah sebagai berikut:

$\begin{array}{ll}\text { Kingdom } & \text { : Animalia } \\ \text { Phylum } & \text { : Arhtropoda } \\ \text { Kelas } & \text { : Insecta } \\ \text { Ordo } & \text { : Isoptera } \\ \text { Famili } & \text { : Termitidae } \\ \text { Subfamili } & \text { : Nasutitermitinae } \\ \text { Genus } & \text { Nasutitermes } \\ \text { Spesies }: \text { Nasutitermes matangensis }\end{array}$

Berdasarkan hasil survei penelitian di Pulau Sebesi Lampung menunjukan bahwa ditemukan sarang rayap Nasutitermes matangensis yang tersebar secara acak, seperti tersusun pada gambar dibawah ini: 


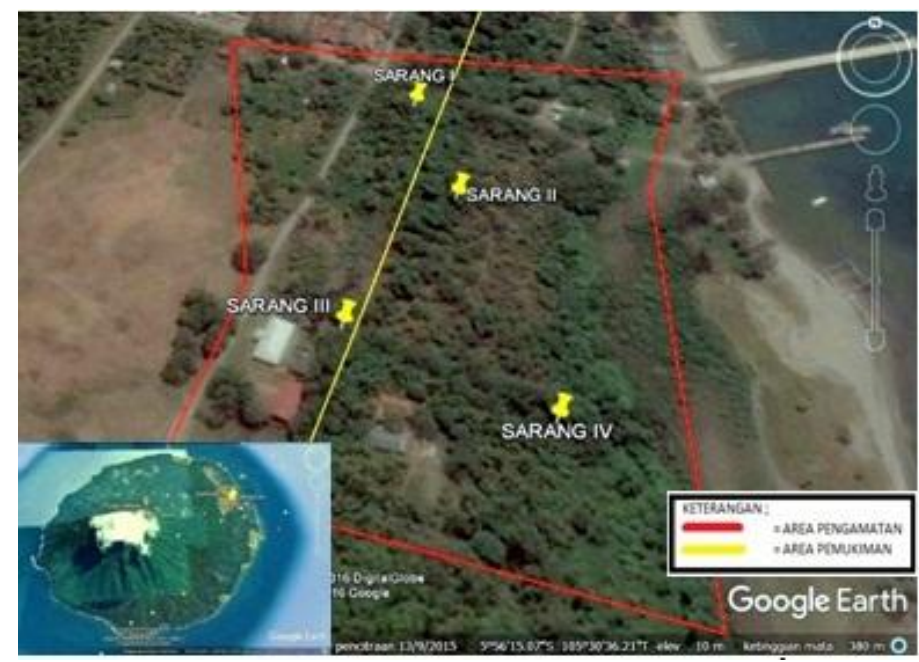

Rayap (termite) adalah serangga bertubuh lunak yang umumnya dikenal sebagai semut putih. Namun rayap bukanlah semut mereka memiliki 3 bagian tubuh utama yaitu kepala, dada (thorak) dan perut (abdomen). Rayap memiliki sistem sosial, dengan raja, ratu, pekerja, dan tentara. Morfologi yang berbeda-beda sehingga memiliki sistem pembagian tugas dan seperti halnya rayap ratu memiliki ukuran yang lebih besar untuk menghasilkan anak, sedangkan rayap prajurit memiliki mulut bertipe pengigit dengan capit yang lebih besar

Tho tahun 1992, rayap ini termasuk ke dalam ordo Isoptera, famili Termitidae, subfamili Nasutitermitinae, genus Nasutitermes dan spesies Nasutitermes matangensis Haviland. Famili termitidae Berdasarkan kunci identifikasi rayap spesies rayap tingkat tinggi, mayoritas anggota dari rayap familiTermitidae memakan kayu, rumput dan termasuk lumut.

Adapun ciri morfologi rayap Nasutitermes ini sebagai berikut : pemakan kayu (wood feeders) dan sarangnya berada dipohon (aborael nest), kepala bewarna kuning berbentuk bulat, membentuk nasut dengan fontanel di ujungnya, panjang kepala dan 
nasut $1,25 \mathrm{~mm}$, yang tanpa nasut $0,65 \mathrm{~mm}$, lebar kepala $0,72 \mathrm{~mm}$, antena pendek dari ruas ketiga. Nasut prajurit berbentuk kerucut dengan bagian pangkal manebel dan agak melengkung.

Jika diperhatikan rayap akan saling menjilati, mencium, atau menggosokan tubuhnya satu sama lain ketika bertemu, perilaku rayap ini disebut trofaksi. Hal ini merupakan cara rayap untuk berkomunikasi dikarenakan rayap adalah serangga yang buta. Melalui cara ini rayap akan saling menyalurkan makanan, feromon, atau protozoa flagellata yang sangat berperan dalam kehidupan koloni rayapJika diperhatikan rayap akan saling menjilati, mencium, atau menggosokan tubuhnya satu sama lain ketika bertemu, perilaku rayap ini disebut trofaksi. Hal ini merupakan cara rayap untuk berkomunikasi dikarenakan rayap adalah serangga yang buta. Melalui cara ini rayap akan saling menyalurkan makanan, feromon, atau protozoa flagellata yang sangat berperan dalam kehidupan koloni rayap.

Feromon adalah sinyal berupa senyawa kimia yang membawa informasi dari satu individu ke individu lain pada spesies yang sama (intraspesifik) sedangkan allelochemical adalah sinyal berupa senyawa kimia yang membawa pesan dari satu individu ke individu lain yang berbeda spesies (interspesifik).

Feromon yang sama digunakan sepasang serangga mungkin memiliki sumber kelenjar yang berbeda. Misalnya, disekresikan oleh kelenjar sternum hipertrofi betina dari Pseudacanthotermes spiniger, dan kelenjar dibagian punggung dari Cornitermes bequaerti. 


\section{METODE}

Penelitian ini dilakukan pada bulan November 2016 pengambilan sampel di Pulau Sebesi Lampung dan pemeliharaan di Laboratorium IAIN Raden Intan Lampung. Tahap yang dilakukan pada penelitian adalah identifikasi spesies kemudian pengamatan perilaku agonistik intraspesifik koloni rayap Nasutitermes matangensis.

Alat dan bahan yag digunakan adalah adalah GPS, kampak, cawan petri, silver pen, kamera, filter ekstraktor, mikroskop, labu bundar, tabel pengamatan, kertas label dan alat tulis. Bahan yang digunakan dalam penelitian ini adalah kasta prajurit dan kasta pekerja dari rayap Nasutitermes matangensis yang di ambil dari di Pulau Sebesi Lampung Selatan.

Teknik yang digunakan untuk pengambilan sampel pada penelitian ini adalah Direct sampling yaitu dengan cara pengambilan sampelnya secara langsung yang dilakukan di Pulau Sebesi Lampung dan kemudian dilanjutkan dengan Purposive sampling

Koloni rayap terbentuk dari sepasang laron betina dan jantan yang terbang secara berkelompok dari sarangnya, kemudian mencari pasangan. Masing-masing pasangan laron tersebut kemudian beriringan menuju tempat yang dipilih untuk kawin dan membuat sarang. Laron betina berperan sebagai ratu primer, sedangkan laron jantan sebagai raja. Telur yang dihasilkan dari perkawinan ratu dan raja tersebut akan menetas dalam rentang waktu yang bervariasi tergantung pada jenisnya.

Pencatatan dan pemetaan persebaran sarang rayap menggunakan GPS (Global Positioning System) pada hutan rimba yang terdapat banyak sarang rayap Nasutitermes matangensis. 
Pengindentifikasi pada setiap sarang yang ditemukan dan diambil sampel sebanyak 5 individu rayap, kemudian rayap dimasukan ke dalam tabung spesimen yang berisi alkohol $70 \%$ dan di beri label. Jika identifikasi sampel menunjukan spesies Nasutitermes matangensis, maka penelitian ini akan dilanjutkan ketahap selanjutnya. Jika tidak menunjukan spesies Nasutitermes matangensis, maka dilakukan identifikasi sampai ditemukan rayap spesies Nasutitermes matangensis.

\section{HASIL}

Hasil penelitian menunjukan perilaku agonistik intraspesifik individu rayap Nasutitermes matangensis dari kombinasi prajurit versus prajurit, pekerja versus pekerja, dan prajurit verus pekerja. Masing-masing dari kombinasi menunjukan perilaku agonistiknya negatif (-). Perilaku setiap kombinasi dari tabel uji agonistik individu rayap prajurit versus prajurit dari koloni yang berbeda hanya menunjukkan sampai pada level antenasi dan menghindar pada tabel 4 (seluruh kombinasi perilaku persentase $0,00 \%$ ), tidak menunjukkan perilaku menyerang sehingga bisa dinyatakan prajurit versus prajurit berstatus negatif (-), sedangkan kombinasi individu rayap pekerja versus pekerja dan prajurit versus pekerja menunjukkanperilaku pada level antenasi, menghindar dan menyerang, akan tetapi dapat dilihat pada tabel 5 dan 6 bahwa level perilaku menyerang persentase $0,00 \%-13,33 \%$.

Perilaku agonistik dinyatakan positif $(+)$ jika persentase perilaku menyerang $\geq$ $80 \%$ sedangkan jika perilaku menyerang $\leq 20 \%$ maka status agonistik dinyatakan negatif (-).

Hasil data yang didapat adalah sebagai berikut : 
Tabel 5.Uji Individu Rayap Pekerja Versus Pekerja

\begin{tabular}{|l|c|c|c|c|c|}
\hline \multirow{2}{*}{ No } & \multirow{2}{*}{ Kombinasi } & \multicolumn{3}{|c|}{ Perilaku } & $\begin{array}{c}\text { Status } \\
\text { Agonistik }\end{array}$ \\
\cline { 3 - 5 } & & Antenasi & Menghindar & Menyerang & - \\
\hline 1 & $\mathrm{Pk}_{\mathrm{a}}-\mathrm{Pk}_{\mathrm{a}}$ & $100,00 \%$ & $100,00 \%$ & $0,00 \%$ & - \\
\hline 2 & $\mathrm{Pk}_{\mathrm{b}}-\mathrm{Pk}_{\mathrm{b}}$ & $100,00 \%$ & $100,00 \%$ & $0,00 \%$ & - \\
\hline 3 & $\mathrm{Pk}_{\mathrm{c}}-\mathrm{Pk}_{\mathrm{s}}$ & $100,00 \%$ & $100,00 \%$ & $0,00 \%$ & - \\
\hline 4 & $\mathrm{Pk}_{\mathrm{s}}-\mathrm{Pk}_{\mathrm{s}}$ & $100,00 \%$ & $100,00 \%$ & $0,00 \%$ & - \\
\hline 5 & $\mathrm{Pk}_{\mathrm{a}}-\mathrm{Pk}_{\mathrm{b}}$ & $90,00 \%$ & $100,00 \%$ & $6,67 \%$ & - \\
\hline 6 & $\mathrm{Pk}_{\mathrm{a}}-\mathrm{Pk}_{\mathrm{s}}$ & $90,00 \%$ & $93,33 \%$ & $13,33 \%$ & - \\
\hline 7 & $\mathrm{Pk}_{\mathrm{a}}-\mathrm{Pk}_{\mathrm{s}}$ & $86,67 \%$ & $100,00 \%$ & $6,67 \%$ & - \\
\hline 8 & $\mathrm{Pk}_{\mathrm{b}}-\mathrm{Pk}_{\mathrm{s}}$ & $93,33 \%$ & $90,00 \%$ & $13,33 \%$ & - \\
\hline 9 & $\mathrm{Pk}_{\mathrm{b}}-\mathrm{Pk}_{\mathrm{s}}$ & $90,00 \%$ & $90,00 \%$ & $13,33 \%$ & - \\
\hline 10 & $\mathrm{Pk}_{\mathrm{c}}-\mathrm{Pk}_{\mathrm{s}}$ & $93,33 \%$ & $100,00 \%$ & $0,00 \%$ & - \\
\hline
\end{tabular}

Tabel 4. Uji Individu Rayap Prajurit Versus Prajurit

\begin{tabular}{|c|c|c|c|c|c|}
\hline \multirow{2}{*}{ No } & \multirow{2}{*}{ Kombinasi } & \multicolumn{3}{|c|}{ Perilaku } & $\begin{array}{c}\text { Status } \\
\text { Agonistik }\end{array}$ \\
\cline { 3 - 5 } & & Antenasi & Menghindar & Menyerang & - \\
\hline 1 & $\mathrm{Pr}_{\mathrm{a}}-\mathrm{Pr}_{\mathrm{a}}$ & $100,00 \%$ & $100,00 \%$ & $0,00 \%$ & - \\
\hline 2 & $\mathrm{Pr}_{b}-\mathrm{Pr}_{b}$ & $100,00 \%$ & $100,00 \%$ & $0,00 \%$ & - \\
\hline 3 & $\mathrm{Pr}_{\mathrm{c}}-\mathrm{Pr}_{\mathrm{c}}$ & $100,00 \%$ & $100,00 \%$ & $0,00 \%$ & - \\
\hline 4 & $\mathrm{Pr}_{b}-\mathrm{Pr}_{b}$ & $100,00 \%$ & $100,00 \%$ & $0,00 \%$ & - \\
\hline 5 & $\mathrm{Pr}_{\mathrm{a}}-\mathrm{Pr}_{b}$ & $96,67 \%$ & $100,00 \%$ & $0,00 \%$ & - \\
\hline 6 & $\mathrm{Pr}_{\mathrm{a}}-\mathrm{Pr}_{\mathrm{c}}$ & $90,00 \%$ & $100,00 \%$ & $0,00 \%$ & - \\
\hline 7 & $\mathrm{Pr}_{\mathrm{a}}-\mathrm{Pr}_{b}$ & $90,00 \%$ & $96,67 \%$ & $0,00 \%$ & - \\
\hline 8 & $\mathrm{Pr}_{b}-\mathrm{Pr}_{c}$ & $100,00 \%$ & $100,00 \%$ & $0,00 \%$ & - \\
\hline 9 & $\mathrm{Pr}_{b}-\mathrm{Pr}_{b}$ & $93,33 \%$ & $93,33 \%$ & $0,00 \%$ & - \\
\hline 10 & $\mathrm{Pr}_{c}-\mathrm{Pr}_{b}$ & $90,00 \%$ & $96,67 \%$ & $0,00 \%$ & - \\
\hline
\end{tabular}

Tabel 6. Uji Individu Rayap Prajurit Versus Pekerja

\begin{tabular}{|c|c|c|c|c|c|}
\hline \multirow[t]{2}{*}{ No } & \multirow[t]{2}{*}{ Kombinasi } & \multicolumn{3}{|c|}{ Perilaku } & \multirow{2}{*}{$\begin{array}{c}\text { Status } \\
\text { Agonistik }\end{array}$} \\
\hline & & Antenasi & Menghindar & Menyerang & \\
\hline 1 & $\mathrm{Pr}_{\mathrm{a}}-\mathrm{Pk}_{\mathrm{a}}$ & $100,00 \%$ & $100,00 \%$ & $0,00 \%$ & - \\
\hline 2 & $\mathrm{Pr}_{\mathrm{b}}-\mathrm{Pk}_{\mathrm{b}}$ & $100,00 \%$ & $100,00 \%$ & $0,00 \%$ & - \\
\hline 3 & $\mathrm{Pr}_{\mathrm{c}}-\mathrm{Pk}_{\mathrm{c}}$ & $100,00 \%$ & $100,00 \%$ & $0,00 \%$ & - \\
\hline 4 & $\mathrm{Pr}_{\delta}-\mathrm{Pk}_{\delta}$ & $100,00 \%$ & $100,00 \%$ & $0,00 \%$ & - \\
\hline 5 & $\mathrm{Pr}_{\mathrm{a}}-\mathrm{Pk}_{\mathrm{b}}$ & $90,00 \%$ & $83,33 \%$ & $13,33 \%$ & - \\
\hline 6 & $\mathrm{Pr}_{\mathrm{a}}-\mathrm{Pk}_{\mathrm{s}}$ & $90,00 \%$ & $80,00 \%$ & $13,33 \%$ & - \\
\hline 7 & $\mathrm{Pr}_{\mathrm{a}}-\mathrm{Pk}_{\delta}$ & $100,00 \%$ & $100,00 \%$ & $0,00 \%$ & - \\
\hline 8 & $\mathrm{Pr}_{\mathrm{b}}-\mathrm{Pk}_{\mathrm{c}}$ & $100,00 \%$ & $96,67 \%$ & $6,67 \%$ & - \\
\hline 9 & $\mathrm{Pr}_{\mathrm{b}}-\mathrm{Pk}_{\mathrm{s}}$ & $86,67 \%$ & $96,67 \%$ & $6,67 \%$ & - \\
\hline 10 & $\mathrm{Pr}_{r_{c}}-\mathrm{Pk}_{\mathrm{s}}$ & $93,33 \%$ & $100,00 \%$ & $0,00 \%$ & - \\
\hline 11 & $\mathrm{Pr}_{\mathrm{b}}-\mathrm{Pk}_{\mathrm{a}}$ & $100,00 \%$ & $100,00 \%$ & $0,00 \%$ & - \\
\hline 12 & $\mathrm{Pr}_{\mathrm{c}}-\mathrm{Pk}_{\mathrm{a}}$ & $93,33 \%$ & $100,00 \%$ & $0,00 \%$ & - \\
\hline 13 & $\mathrm{Pr}_{\sigma}-\mathrm{Pk}_{\mathrm{a}}$ & $93,33 \%$ & $100,00 \%$ & $0,00 \%$ & - \\
\hline 14 & $\mathrm{Pr}_{\mathrm{c}}-\mathrm{Pk}_{\mathrm{b}}$ & $90,00 \%$ & $100,00 \%$ & $0,00 \%$ & - \\
\hline 15 & $\mathrm{Pr}_{r_{\sigma}}-\mathrm{Pk}_{\mathrm{b}}$ & $100,00 \%$ & $96,67 \%$ & $0,00 \%$ & - \\
\hline 16 & $\mathrm{Pr}_{\delta}-\mathrm{Pk}_{\mathrm{s}}$ & $96,67 \%$ & $96,67 \%$ & $0,00 \%$ & - \\
\hline
\end{tabular}

\section{Keterangan}

$\begin{array}{ll}\text { Sampel individu koloni } & : \text { a, b, c, dan d } \\ \mathrm{Pr} & \text { : Kasta Prajurit } \\ \mathrm{Pk} & \text { : Kasta Pekerja }\end{array}$


Setelah melakukan tiga kali pengulangan ternyata tidak terjadi agresi dari setiap individu meski rayap Nasutitermes matangensis berbeda koloni dengan jarak yang berjauhan. Perilaku agonistik diamati sebagai perilaku antenasi (pertemuan antar antena), palpasi (bersentuhan tubuh/mencium), alarm (menghindar/mengejar), agresi terdiri dari mengigit, menusuk lawan, tahan atau tarik satu sama lain, dan memperebutan suatu makanan atau lingkungan tempat tinggal.

Perilaku agresif tidak selalu menjamin kelangsungan hidup atau kesempatan yang lebih tinggi untuk melakukan sebuah perlawanan dengan keberlangsungan hidup lawan selama 24 jam setelah pertemuan awal.

Berdasarkan hasil penelitian pada setiap kombinasi rayap prajurit versus prajurit, pekerja versus pekerja, prajurit versus pekerja dan tidak menunjukan adanya perilaku agonistik atau statusagonistik negatif (-) pada rayap Nasutitermes matangensis yang berasal dari Pulau Sebesi Lampung, hal ini menunjukan bahwa perilaku agonistik tidak dipengaruhi oleh koloni rayap Nasutitermes matangensis yang berbeda.

Perilaku rayap kasta prajurit dengan prajurit, pekerja versus pekerja, dan prajurit versus pekerja dari empat koloni yang berbeda pada setiap kombinasi uji tidak menunjukan adanya perilaku agonistik, selama 5 menit pengamatan pertama yang terjadi dalam arena uji cendrung pasif yaitu saling mempertemukan antena, saling mengejar dan menghindar. Rayap kasta prajurit dengan pekerja perilaku yang terjadi serupa dengan kasta prajurit dengan prajurit dimana pada setiap kombinasi uji rayap yang berasal dari empat koloni tersebut tidak menunjukan perilaku agresi atau bertengkar melainkan hanya saling mempertemukan antena atau saling menghindar.

Kombinasi rayap pekerja versus pekerja perilaku yang berhasil diamati pada 5 menit pengamatan pertama dalam arena uji adalah saling mempertemukan antena, 
saling menghindar antara masing-masing rayap dan dalam arena uji tidak terjadi konflik pada setiap kombinasi rayap kasta pekerja. Perilaku agonistik intraspesifik adalah ketika hewan bersama dapat terjadi pertempuran, perebutan sumberdaya, dan agresi, namun demikian terdapat faktorOfaktor yang dapat mengubah perilaku tersebut. Seperti yang dikatakan Daniel A. Bregman dan Paul A. Moore faktor ekstrinsik dan intrisik dapat mempengaruhi agresi intraspesifik, dan keduanya diakui memiliki potensi mengubah perilaku.

Komponen senyawa volatil utama yang berperan dalam perilaku berkawan rayap Nasutitermes matangensis yaitu tidak terjadi agresi saat dipertemuan dalam satu tempat yang sama meski rayap-rayap ini berasal dari koloni yang berbeda dan dikumpulkan dari tempat yang berjauhan adalah suatu komponen senyawa volatil yang disebut feromon. Seperti yang sudah dituliskan pada bab sebelumnya bahwa feromon adalah senyawa kimia yang dikeluarkan oleh individu satu speies serangga yang dapat mempengaruhui perilaku individu lain dari spesies yang sama. "Istilah feromon (pheromone) berasal dari bahasa Yunani, yaitu phero yang artinya pembawa dan mone sensasi. Sifat senyawa feromon adalah tidak dapat dilihat oleh mata, volatil (mudah menguap), tidak dapat diukur, tetapi ada dan dapat dirasakan.

Feromon inilah yang menjadi media komunikasi antara individu satu dengan individu lainnya dalam suatu spesies serangga, "zat ini berasal dari kelenjar endokrin, berbeda dengan feromon, feromon menyebar keluar tubuh hanya dapat dikenali oleh individu lain yang sejenis (satu spesies). 


\section{KESIMPULAN DAN SARAN}

Berdasarkan hasil penelitian dan pembahasan dapat disimpulkan bahwa :

Intraksi antar individu prajurit versus prajurit, pekerja versus pekerja, dan prajurit versus pekerja dari koloni yang berbeda pada spesies Nasutitermes matangensis di Pulau Sebesi Lampung status agonistik negatif (-).Uji agonistik prajurir versus prajurit menunjukkan perilaku antena persentasi $90,00 \%$ - 100,00\%, perilaku menghindar $93,33 \%$ - 100,00\%, dan menyerang persentase 0,00\%.Uji agonistik pekerja versus pekerja menunjukkan perilaku antenasi persentase $86,67 \%$ - 100,00\%, perilaku menghindar persentase $90,00 \%$ - 100,00\%, dan perilaku menyerang persentase $0,00 \%$ $13,33 \%$ dan uji agonistik prajurit versus pekerja menunjukkan perilaku antenasi persentase $86,67 \%-100,00 \%$, perilaku menghindar persentase $80,00 \%-100,00 \%$, dan perilaku menyerang persentase $0,00 \%$ - $13,33 \%$. Perilaku yang terjadi pada rayap Nasutitermes matangensis adalah saling mempertemukan antena, saling menghindar dan mengejar dan tidak terjadi pertengkaran dalam setiap kombinasi kasta.

Perlu adanya peneliti lanjutan terutama mengenai perilaku agonistik intraspesifik rayap Nasutitermes matangensis pada pulau terdepan Provinsi Lampung. Perlu penelitian yang lebih intensif untuk mengetahui faktor lain yang menyebabkan terjadinya agonistik intraspesifik pada rayap Nasutitermes matangensis.

\section{DAFTAR PUSTAKA}

Asmaliyah, Imanullah Andika, dan Darwiati Wida. 2012. Identifikasi dan Potensi Kerusakan Rayap pada Tanaman Tembesu (Fagraea fragrans) di Kebun Percobaan Way Hanakau Lampung Utara. (Balai Penelitian Kehutanan Palembang)

Austin JW, SzalanskiAL, ScheffrahnRH et al. 2005. Genetic evidence for the synonymy of two Reticulitermes species : Reticulitermes flavipes and Reticulitermes santonensis. Am Entomol Soc Am. 98:395 
Bergman A. Daniel and Moore A. Paul. 2003. Field Observations of Intraspecific Agonistic Behavior of Two Crayfish Species, Orconectes rusticus and Orconectes virilis, in Different Habitats, (Universitas of Michigan Biological Station)

Bignell Edward David, Roisin Yves, Editors Lo Nathan. 2011. Biology Of Termites : A Modern Synthesis. Spinger Science Business Media B.V.

BordereauC, CancelloEM, SemonE et al. 2002. Sex pheromone identified after solid phase microextraction from tergal glands of female alates in Cornitermes bequaerti (Isoptera: Nasutitermitinae). Insectes Soc. 49:209

BordereauC, RobertA, BonnardO, dan Le-QuereJ.L. 1991. (3Z,6Z,8E)-3,6,8dodecantrien-1-ol : Sex Pheromone in a Hingher Fugus-growinary termite, Pseudacanthotermes spinger (Isoptera, Macrotermitinae) Journal of chemical ecologi, 17.2177-2191

Daniel A. Bregmen and Paul A. Moore, 2003, Field Observations of Intraspesific Agonistic Behavior of Two Crayfish Species, Orconectes rusticus and Orconectes virilis, in Defferent Habitats, Universitas of Michigan Biological Station.

Grace JK, Wood DL, Kubo I, dan Kim M, 1995, Trail-following behavior of Reticulitermes hesperus Banks (Isoptera : Rhinotermitidae). J Chem Encol. 119:501.

Gullan P.J dan Cranston P.S, 2005, The Insects : An Outline of Entomology, Blackwell Publishing.

Hasi H.S Singgih dan Kusumawati, 2006, Hama Pemukiman Indonesia, Institut Pertanian Bogor, Bogor.

Iswanto Heri Apri. 2005. Rayap Sebagai Serangga Perusak Kayu dan Metode Penanggulangannya. Fakultas Pertanian Universitas Sumatera.

Kuswanto Eko,. 2015. Keanekaragaman Spesies, Status Hama, Kompetisi Intraspesifik, Dan Upaya Pengendalian Rayap (Insekta : Isoptera) Di Kota Bandung. Disertasi. Institut Teknologi Bandung.

Ladugue N, Robert A, Bonnard O. 1994. Isolation and Identification of (3Z, 6Z, 8E)3,6,8-dodecatrien-1-ol in Reticultermes santonensisFeytaud (Isoptera : Rhinotermitidae) : roles in worker trail-following and in alate sex-attraction behaviour. J. Insect physiol.

Matsumura K, Himuro C, Yok T, Yamamoto Y, Vargo E.L dan Kelle. 2010. Identofication of a pheromone Regulating Caste Differents in Termite, Proceedings of the Nationak Academy of Sciences, 107, 12963-12968. 
Ningsih Surya Deffi, Julia Ridha Za'aziza, Hilmi Larissa, Darmi Leo. 2013. Rayap Kayu (Isoptera) Pada Rumah-rumah Adat Minangkabau Di Sumatera Barat. (Universitas Andalas Padang).

Olugbemi. 2012. Intra-and Inter-colonial Agonistik Behavior in the Termite, Macrotermes fuscotibialis Sjostedt (Isoptera : Termitidae), J Insect Behavior 26:69-78

Prasetiyo Wiji Kurnia, Yusuf Sulaiman. 2005. Mencegah dan Membasmi Rayap Secara Ramah Lingkungan dan Kimiawi. Depok : Agromedia Pustaka

Pratama Sari Oktina Anisa. Kuswanto Eko. 2012. Sebaran dan Ukuran Koloni Sarang Rayap Pohon Nasutitermes sp (Isoptera : Termitidae) Journal of di Pulau Sebesi Lampung Sebagai Sumber Belajar Biologi.

Rismayanti, Arinama. 2007. Usir Rayap dengan Cara Baru dan Ramah Lingkungan. Jakarta : Gramedia.

Rosaria Ina. Kuswanto Eko. 2015. Kajian perilaku agonistik interspesifik koloni rayap Coptotermes sp (Isoptera : Rhinotermitidae) (skripsi).

Hasan Kurniawan Dwi Moh. dan Darwisah, Peta Pulau Sebesi Lampung, ww//http.google_earth. diakses.html tanggal 9 Desember 2017, pukul 15.30 WIB. 